\title{
REPRESENTAÇÕES SOCIAIS DE INOVAÇÃO PEDAGÓGICA POR PROFESSORES DA EDUCAÇÃ̃ BÁSICA
}

\author{
REPRESENTACIONES SOCIALES DE INNOVACIÓN PEDAGOGICA POR \\ PROFESORES DE LA EDUCACIÓN BASICA
}

\section{SOCIAL REPRESENTATION OF PEDAGOGICAL INNOVATION BY TEACHERS OF BASIC EDUCACION}

\author{
Silvio Duarte DOMINGOS ${ }^{1}$ \\ Monica Rabello DE CASTRO²
}

RESUMO: A legislação e as políticas públicas para a Educação, bem mais que abrir o espaço para a inovação em práticas pedagógicas, a coloca como um fator primordial para a melhoria na Educação no Brasil. Entretanto, não se pode falar em inovação nesse campo sem olhar para o professor, que é fundamental nesse campo. Tendo o docente como agente fundamental na Educação, cabe estar atento à sua prática profissional. A literatura aponta uma lacuna entre o que se fala sobre inovação e o que de fato é feito pelos professores. De modo geral, há um desejo de inovar, mas isso não aparece nas práticas docentes. Assim, os discursos sustentam ideias que são incompatíveis com os contextos educacionais, gerando um abismo entre o que se almeja e o que se realiza. $\mathrm{O}$ objetivo desse estudo foi investigar junto aos professores da Educação Básica, as representações sociais a respeito de Inovação Pedagógica. A pesquisa foi realizada tendo a abordagem processual da Teoria das Representações Sociais, como referencial teórico-metodológico. Dez professores da Educação Básica contribuíram para a pesquisa. Foram utilizadas entrevistas semiestruturadas e observação não participante, as entrevistas foram analisadas com a utilização do Modelo da Estratégia Argumentativa (MEA). Verificou-se que suas representações se objetivam em: mudar, melhorar, diferenciar e novidade e se ancoram em: novas tecnologias e construtivismo, elementos oriundos de sua formação inicial. Concluiu-se que os sujeitos participantes veem Inovação Pedagógica como algo externo a si e, por vezes, distante. Relacionam o termo à tecnologia, não se percebem como sujeitos promotores da inovação e apresentam vários entraves a uma prática pedagógica inovadora.

PALAVRAS-CHAVE: Representações sociais. Inovação pedagógica. Práticas docentes. Educação básica.

RESUMEN:La legislación y las políticas públicas para la educación, mucho más que abrir el espacio para la innovación en prácticas pedagógicas, la colocacomo un factor primordial para la mejora en la educación en el Brasil. Sin embargo, no se puede hablar en innovación en ese campo, sin mirar al profesor, que es fundamental en ese

${ }^{1}$ Universidade Estácio de Sá (UNESA), Rio de Janeiro - RJ - Brasil. Docente do Curso Superior em Design de Moda. ORCID: <http://orcid.org/0000-0001-5249-7512>. E-mail: silvioduarte@ gmail.com ${ }^{2}$ Universidade Estácio de Sá (UNESA), Rio de Janeiro - RJ - Brasil. Professora-assistente no Programa de Educação. ORCID: <http://orcid.org/0000-0002-5371-6374>..E-mail: rabellomonica@uol.com.br 
campo. Teniendo el docentecomo agente fundamental en la educación, cabe estar atento a su práctica profesional. La literatura apunta una brecha entre lo que se habla de innovación y lo que de hecholo hacen los profesores. En general hay un deseo de innovar, pero eso no aparece en las prácticas docentes. Así, los discursos sostienen ideas que son incompatibles con los contextos educacionales, generando un abismo entre lo que se anhela y lo que se realiza. El objetivo de ese estudio fue investigar junto a los profesores de la Educación Básica, las representaciones sociales acerca de Innovación pedagógica. La pesquisa fue realizada teniendo el abordaje procesal de la Teoría de las Representaciones Sociales, como referencial teórico-metodológico. Diez profesores de la Educación Básica contribuyeron para la investigación. Se utilizaron entrevistas semiestructuradas y observación no participante, las entrevistas fueron analizadas con la utilización del Modelo de la Estrategia Argumentativa (MEA). Se verificó que sus representaciones se objetivan en: cambiar, mejorar, diferenciar y novedad y se anclan en: nuevas tecnologías y constructivismo, elementos oriundos de su formación inicial. Se concluyó que los sujetos participantes ven la Innovación Pedagógica como algo externo a si y, a veces, distante. Relacionan el termo a la tecnología, no se percibe como sujetos promotores de la innovación y representan varios obstáculos a una práctica pedagógica innovadora.

PALABRASCLAVE: Representaciones sociales. Innovación pedagógica. Prácticas docentes. Educación básica.

ABSTRACT: Legislation and public policies for Education, rather than opening the space for innovation in pedagogical practices, places it as a primary factor for the improvement in Education in Brazil. However, one cannot speak of innovation in this field, without looking at the teacher, who is fundamental in this field. Having the teacher as a fundamental agent in Education, it is necessary to be attentive to their professional practice. The literature points to a gap between what is said about innovation and what is actually done by teachers. In general, there is a desire to innovate, but this does not appear in teaching practices. Thus, discourses sustain ideas that are incompatible with educational contexts, generating an abyss between what is sought and what is realized. The objective of this study was to investigate with the teachers of Basic Education, the social representations regarding Pedagogical Innovation. The research was carried out taking the procedural approach of Theory of Social Representations, as a theoretical-methodological reference. Ten Basic Education teachers contributed to the research. Semi-structured interviews and non-participant observation were used, interviews were analyzed using the Argumentative Strategy Model (MEA). It was verified that their representations are aimed at: change, improve, and differentiate and novelty and anchor themselves in: new technologies and constructivism, elements from their initial formation. It was concluded that the participating subjects see Pedagogical Innovation as something external to themselves and sometimes distant. They relate the term to technology, do not perceive themselves as subjects that promote innovation and present several obstacles to an innovative pedagogical practice.

KEYWORDS: Social representations. Pedagogical innovation. Teaching practices. Basic education. 


\section{Introdução}

No final do ano de 2015, o Ministério da Educação - MEC divulgou o Mapa de Inovação e Criatividade na Educação Básica. Essa iniciativa gerou grande comoção nas organizações que ficaram dentro e nas que ficaram fora do mapa e teve como principal objetivo fortalecer as instituições com propostas criativas e inovadoras na Educação Básica. Para identificá-las, o MEC abriu uma chamada pública e 682 entidades se inscreveram. As inscrições foram avaliadas por Grupos de Trabalho - GT regionais, segundo cinco critérios: gestão, currículo, ambiente, metodologia e intersetorialidade ${ }^{3}$. Por fim, foram selecionadas 178 organizações escolares e não escolares, em diversas etapas do ensino no país.

Para o MEC, existem dois campos possíveis para a inovação: um que se dá no sentido de uma qualificação da escola e outro no sentido de uma transformação no modelo educacional existente. Esse segundo é o que tem recebido apoio dessa recente iniciativa. O Ministério incentiva a transformação, pois para ele, alguns processos sociais que se tornaram mais fortes na contemporaneidade exigem mudanças expressivas no campo educacional.

O primeiro desses processos ocorre no mundo do trabalho, em que as relações profissionais estão, a cada dia, menos regulamentadas e as carreiras menos previsíveis. Isso somado à expectativa de vida mais longa e à dinâmica da economia tem possibilitado que as pessoas tenham mais de uma carreira. Essa nova configuração vem tornando cada vez mais fluidas as fronteiras entre as áreas de trabalho, exigindo dos profissionais saberes e competências diversos. A estrutura curricular baseada em disciplinas parece não responder a essas novas demandas.

Uma segunda transformação pode ser percebida pela crescente exigência de atitudes éticas, prudentes e criativas em relação ao planeta. O risco da ausência de futuro torna explícita a necessidade de se criar soluções para resolver problemas que parecem insolúveis. Nesse sentido, é importante que bem mais que memorizar conteúdos as pessoas aprendam a pesquisar e assumir novas atitudes e comportamentos.

Um terceiro processo é marcado pelo impacto social das novas tecnologias de informação e comunicação que modificaram os modos de produção de conhecimento, facilitaram o autoaprendizado, a formação de comunidades de aprendizagem e as redes de produção de conhecimento a baixos custos. Pessoas de todas as idades podem, com

${ }^{3}$ Para o MEC, a intersetorialidade é a relação entre diversos setores e organizações, não apenas as educacionais. 
facilidade, realizar pesquisas sobre assuntos de seu interesse, discuti-los com outras pessoas que vivem próximas ou do outro lado do planeta. Isso oportuniza colocar o estudante como um protagonista de sua própria formação. Da mesma forma, as pessoas podem produzir vídeos e programas de rádio, com facilidade e atingir um público amplo.

De acordo com o MEC, esses processos exigem uma transformação do modelo de educação atual. Segundo o Ministério, um novo modelo educacional é caracterizado pelos seguintes aspectos: O protagonismo do estudante, ou seja, o estudante como autor, aquele que produz o conhecimento com a utilização das novas tecnologias da informação e comunicação - TIC; a perspectiva do território educativo, em que a Escola é vista como insuficiente para garantir todos os direitos educacionais aos estudantes, sendo, portanto, necessária sua articulação com outras organizações, inclusive as instituições não organizacionais. A Educação não é só para garantir o desenvolvimento intelectual ou aprendizado dos conteúdos acadêmicos, mas sim o desenvolvimento integral dos estudantes. Abrange aspectos éticos, afetivos, sociais e corporais; gestão participativa da instituição educacional, em que estudantes, educadores e comunidade participam da gestão escolar, já prevista na legislação brasileira; o ambiente escolar é visto como um ambiente acolhedor, no qual os alunos lidam com seus conflitos de forma construtiva. Nesse sentido, o conflito é compreendido como uma oportunidade para a aprendizagem; a garantia de que cada um aprenda de acordo com seu interesse, habilidade e ritmo. Uma proposta de personalização do ensino, em que cada aluno desenvolva seu currículo da maneira que lhe interesse, acompanhado de um tutor.

Vale mencionar, ainda, que a iniciativa de criar o Mapa da Inovação e Criatividade na Educação Básica teve como objetivos principais:

1. Estabelecer parâmetros e referenciais em inovação e criatividade na educação básica.

2. Conhecer a extensão, a distribuição geográfica e o perfil da inovação e criatividade na educação básica brasileira.

3. Fortalecer as organizações educativas inovadoras e criativas.

4. Ampliar o impacto das experiências inovadoras relevantes para além de seu polo inicial.

5. Criar, ampliar e qualificar a demanda social por educação inovadora e criativa.

6. Promover a formação de educadores abertos e qualificados para a inovação e criatividade.

7. Promover a reorientação das políticas públicas de educação básica a partir do referencial da criatividade e inovação. (MINISTÉRIO DA EDUCAÇÃO, 2015). 
A proposta de incentivo à inovação na Educação Básica apoiou-se na legislação para a Educação, como no texto da LDB de 1996, que flexibiliza e abre possibilidades diversas para a organização escolar. Nela é explicito que os sistemas de ensino têm liberdade de organização, além disso, o Art. 15 explica que é assegurado às unidades escolares públicas de Educação Básica, que integram diferentes sistemas de ensino, progressivos graus de autonomia pedagógica. Já no Art. 23 fica claro que a Educação Básica:

Poderá organizar-se em séries anuais, períodos semestrais, ciclos, alternância regular de períodos de estudos, grupos não-seriados, com base na idade, na competência e em outros critérios, ou por forma diversa de organização, sempre que o interesse do processo de aprendizagem assim o recomendar. (LEI DE DIRETRIZES E BASES DA EDUCAÇÃO NACIONAL, 1996).

Nesse mesmo sentido, as Diretrizes Curriculares Nacionais de 2013 afirmam que a qualidade na Escola exige de professores, como de todos os sujeitos envolvidos na educação, habilidades inovadoras, capazes de aplicar técnicas e tecnologias. Esclarecem que os cursos de formação inicial e continuada de professores devem levar em consideração que o aluno, futuro professor, precisa desenvolver habilidades com fundamento na ética da inovação. Segundo as Diretrizes, "são também importantes metodologias de ensino inovadoras, distintas das que se encontram nas salas de aula mais tradicionais" (MEC, 2013).

O Plano Nacional da Educação - PNE, de 2014, que tem como uma de suas metas a alfabetização de crianças até o final do terceiro ano do ensino fundamental, propõe, como principal estratégia para chegar a esse objetivo, o fomento à inovação de práticas pedagógicas. Em paralelo, a décima edição do Prêmio Professores do Brasil, realizada em 2017, proposta pelo Ministério da Educação, premiará professores com práticas que estimulem o conhecimento científico por meio da inovação.

Está bastante claro que a legislação, bem mais que abrir o espaço para a inovação em práticas pedagógicas, coloca-a como um fator primordial para a melhoria na Educação no Brasil. Entretanto, não se pode falar em inovação na Educação Básica sem olhar para a fundamental figura do professor, conforme aponta Tardif (2002, p. 228), o professor ocupa "uma posição fundamental em relação ao conjunto dos agentes escolares”. Esse pesquisador vê o professor como um elo entre os diversos sujeitos da educação e, por isso, defende o estudo sobre sua formação. Libâneo (2007, p. 83) percebe essa implicação direta na qualidade do aprendizado do aluno, alertando que "é 
certo que a formação geral de qualidade dos alunos depende da formação de qualidade dos professores", portanto, o agente no processo educacional, que principalmente é impactado pelas políticas e premiações que incentivam a inovação é o docente. Portanto, é necessário entender como tantos incentivos influenciam as práticas pedagógicas de docentes na Educação Básica. Este é, sem dúvidas, o principal alvo das políticas voltadas à inovação no campo educacional.

Tendo o docente agente fundamental na Educação, cabe estar atento à sua prática profissional. Gomes (2006, p.9) salienta a lacuna existente entre o que se teoriza e se idealiza e o significado, a autora indica que alguns professores "apresentaram intenções de inovações em suas concepções de conhecimento pedagógico", a lacuna decorre "por se estar falando mais sobre o que deveria ser feito pelo futuro docente, pelo curso de formação e pela escola, do que fazendo o que deveria ser feito".

Assim, os professores da Educação básica não praticam aquilo que dizem ser uma boa prática. Conforme mostra a literatura, na maioria das vezes os discursos sustentam ideias que são incompatíveis com os contextos educacionais, gerando um abismo entre o que se almeja e o que se realiza. De acordo com a autora:

Pode-se verificar que existe uma grande distância entre o que seria o ideal de Educação, tanto em nível de Ensino Fundamental, quanto de Ensino Médio, e na formação dos professores que estarão atuando nestes níveis, e o que é real em nossa Educação, principalmente no que diz respeito aos cursos de formação de professores. (GOMES, 2006, p. 10)

Quanto ao preferível, parece ser referência o texto do Parecer $\mathrm{CNE} / \mathrm{CP} \mathrm{n}^{\circ}$ 9, de oito de maio de 2001:

- Exigências para consolidar a formação de professores educadores, com relação aos alunos do Ensino Fundamental e Médio: valorizar o conhecimento e os bens culturais e ter acesso a eles autonomamente, selecionar o que é relevante, investigar, questionar e pesquisar; construir hipóteses, compreender, raciocinar logicamente; comparar, estabelecer relações, inferir e generalizar; adquirir confiança na própria capacidade de pensar e encontrar soluções. Preconiza, ainda, que é preciso que todos aprendam a relativizar, confrontar e respeitar diferentes pontos de vista, discutir divergências, exercitar o pensamento crítico e reflexivo; aprender a ler criticamente diferentes tipos de textos, utilizar diferentes recursos tecnológicos, expressar-se em várias linguagens, opinar, enfrentar desafios, criar, agir de forma autônoma, diferenciar o espaço público do espaço privado, ser solidários, conviver com diversidades e repudiar qualquer tipo de discriminação. 
- Um educando deve ser capaz de construir o seu conhecimento através da interação com o mundo e com os outros; aprender de um jeito próprio e específico e, um educador deve ser capaz de preparar o educando para se relacionar com as incertezas, sendo mais pesquisador do que transmissor; compromete-se com o futuro no presente da sala de aula, está preocupado com a atualização constante, negociando propostas curriculares mais flexíveis e adaptáveis às condições intelectuais e emocionais dos educandos no seu contexto de atuação.

Quanto ao real, o que apontam os estudos é que as práticas pedagógicas atuais muitas vezes apenas replicam o que está prescrito no currículo, assim, separam, fragmentam e compartimentam saberes entre disciplinas, diante de problemas multidimensionais, globais, transversais e transnacionais (MORIN, 2000; CÂNDIDO, 2013). Nesse sentido, Behrnes (2005) aponta que, esse modo tradicional de exercer a prática docente, ocorre por aulas, meramente, expositivas e demonstrativas. Esse tipo de trabalho se baseia em quatro pilares: escute, leia decore e repita. A partir do método indutivo, a metodologia privilegia a lógica, a sequência ordenada dos conteúdos, visando disciplinar a mente e a formação de hábitos.

Essa Escola, tradicionalista e ultrapassada é criticada por desconsiderar questões sociais envolvidas no processo ensino-aprendizagem, assim, os professores se preocupam apenas em transmitir o patrimônio cultural. Mizukami (1986) lembra que a escola é um ambiente austero e conservador, parecendo-se mais uma cadeia que um centro educativo. Tudo o que há nesse modelo de escola é relacionando à prisão, como os conceitos de disciplina e grade curricular, por exemplo.

Existem pesquisas que apontam a escola como fruto de um modelo industrial taylorista-fordista, assim, a modernização social molda nossos valores e o modo como concebemos a educação (DOLL, 2002; CABRAL; CASTRO, 2007). Do mesmo modo que na indústria, a escola volta-se à produtividade e segue regras rígidas de horário e comportamento, o poder é centralizado e hierarquizado. Por fim, esse modo de exercer a prática docente tem como função preparar moralmente e intelectualmente os alunos para que assumam seu papel social.

Os pesquisadores, que discutem a inovação pedagógica na Educação, buscam opô-la à noção de uma escola tradicional e ultrapassada. Reivindicam a criação de contextos de aprendizagem incomuns aos habituais nas escolas, contextos que se distanciem de aparentes ambientes fabris ou prisionais, percepção que surge a partir de 
denúncias como as de Foucault (1977), para quem a escola tende a disciplinar o homem para a servidão, segundo padrões de condutas, pois:

Combina as técnicas da hierarquia que vigia e as da sanção que normaliza. É um controle normalizante, uma vigilância que permite qualificar, classificar e punir. Estabelece sobre os indivíduos uma visibilidade através da qual eles são diferenciados e sancionados. É por isso que em todos os dispositivos de disciplina o exame é altamente ritualizado. Nele vêm-se reunir a cerimônia do poder e a forma da experiência, a demonstração da força e o estabelecimento da verdade. No coração dos processos de disciplina, ele manifesta a sujeição dos que são percebidos como objetos e a objetivação dos que se sujeitam. A superposição das relações de poder e das de saber assume no exame todo o seu brilho visível. (FOUCAULT, 1977, p. 164-165).

Esse é o problema que os críticos a uma prática pedagógica tradicional indicam. Essa ideia de "tradicional", em Foucault, sugere que a escola adestra as mentes e os corpos dos sujeitos à obediência. O homem é visto como um elemento domesticável, um objeto moldável, que não infrinja as regras do poder, que se expande pela sociedade como uma rede. Em Foucault, a escola é um disciplinador do homem, uma instituição capaz de arrebatar e preparar grandes massas humanas à obediência, submissão e ao trabalho para a geração de força. Sob a alegação de detentora da verdade, a escola fabrica indivíduos, ao passo que lhes embute um conjunto de valores, crenças e saberes forjados historicamente. A organização física dessa escola remete aos aspectos de fábricas, hospitais, manicômios e presídios, todos promoveriam o adestramento do homem e sua disciplina corporal.

O poder disciplinar é com efeito um poder que, em vez de se apropriar e de retirar, tem como função maior 'adestrar'; ou sem dúvida adestrar para retirar e se apropriar ainda mais e melhor. Ele não amarra as forças para reduzi-las; procura ligá-las para multiplicá-las e utilizá-las como um todo. (FOUCAULT, 1987, p. 143).

O poder disciplinar estabelecido pela escola não apenas minimiza ou aprisiona o indivíduo, para o autor, ele o adestra, torna-o dócil, maleável e moldável; conecta as forças individuais para utilizá-las com uma rede mecânica, sendo suas principais técnicas disciplinares, o quadriculamento, o controle do horário, a clausura, o treinamento, a sanção normatizadora e o teste. 
Assim, trabalhos como os de Campos (2016), Fino (2008; 2011), Neto (2012), Gouveia (2012) e Dourado (2014) afirmam que a inovação pedagógica implica rupturas, envolvendo um posicionamento crítico. Esses autores não afastam a ideia de que inovação pedagógica se apoia em fatores pré-existentes que as encorajam e as apoiem, mas defendem que ela não reside nesses fatores. Fino (2008, p. 277) explica que a inovação pedagógica também "consiste na criação de contextos de aprendizagem, incomuns relativamente aos que são habituais nas escolas, como alternativa à insistência nos contextos de ensino". Suas discussões estão em sentido análogo a Kuhn (1970), que explora a noção de mudança ou transformação paradigmática e permite tencionar o conceito aqui discutido a um salto no fazer científico, à medida em que a ruptura é comum à prática científica. Conclui-se que, para os defensores desse posicionamento, inovação pedagógica pressupõe a adoção de uma atitude incompatível com as práticas pedagógicas tradicionais. Em relação às culturas escolares tradicionais, a inovação pedagógica provoca uma ruptura cultural.

Outro pressuposto desses pesquisadores é que a inovação pedagógica não encontra eco no atual modelo de Educação institucionalizado, já que esse modelo tende a preservar práticas pedagógicas tradicionais. O currículo também se constitui como um entrave à inovação, por muitas vezes, chocar-se contra ela.

Após a observação da legislação que abre espaço e até mesmo procura propor a inovação das políticas públicas que buscam promovê-la e até mesmo da literatura sobre o assunto, percebe-se que há um grande vácuo que evidencia a necessidade de estudos sobre a percepção dos professores quanto à inovação.

Para investigar esse problema, que está dimensionado entre a cultura, o social e o psicológico, a Teoria das Representações Sociais, (MOSCOVICI, 1978), é uma das mais adequadas. Quais as representações sociais que professores da Educação Básica têm de inovação pedagógica? Ela permite olhar para o problema em suas múltiplas dimensões, compreendendo seus processos formadores. Desenvolvemos a pesquisa de modo alinhado à abordagem sócio-genética, ou abordagem processual das representações sociais. Tal perspectiva procura, na gênese social da representação, seus processos formadores: objetivação e ancoragem. Como essa perspectiva das representações sociais explora os limites da Antropologia e da Psicologia Social, lançamos mão de estudos de cunho etnográfico. 


\section{Quadro teórico}

A questão da inovação pedagógica tem sido contemplada e incentivadas políticas públicas para a educação. O Mapa da Inovação e da Criatividade, criado pelo MEC, que buscou reconhecer e fortalecer as iniciativas que estimulam a inovação, contribuiu para o surgimento de debates sobre o tema. Essa temática ganhou destaque a partir da divulgação do Mapa, em 2015, no Brasil. Porém, esse assunto circula há algum tempo no cotidiano da educação formal no Brasil. O professor da Educação Básica discute as possibilidades para a melhoraria na Educação no Brasil. Assim, a inovação pedagógica constitui-se como um objeto de representações sociais para os professores, esses são os sujeitos dessa pesquisa.

A Teoria das Representações Sociais (TRS) foi desenvolvida por Serge Moscovici na França, em 1961. Moscovici (2012, p. 39), inicialmente, procura esclarecer que "se a realidade das representações sociais é facilmente apreendida, o conceito não é". Jodelet (1990, p. 22) explica que a representação social é "uma forma de conhecimento, socialmente elaborada e partilhada, com um objetivo prático, e que contribui para a construção de uma realidade comum a um conjunto social". Considerase que a representação social é uma preparação para a ação, isso porque conduz o comportamento e é capaz de modificar e reconstruir os elementos do ambiente em que o comportamento tem lugar.

Assim, busca-se analisar a construção do conhecimento social, abordando aspectos significativos que os sujeitos atribuem a determinados objetos. Os estudos que se utilizam da TRS, segundo Jodelet (1990), permitem observar como o social interfere na elaboração psicológica que constitui a representação e como esta elaboração psicológica interfere no social. Enquanto objeto de estudo da psicologia social, a TRS possibilita a articulação entre o social e o psicológico, pois são os interesses dos grupos que determinam essas representações.

Uma visão funcional do mundo que permite ao indivíduo ou grupo dar sentido a suas condutas e compreender a realidade através de um sistema de referência compartilhado por seu grupo social, logo, adaptar-se e definir seu lugar nessa realidade. É ao mesmo tempo o produto e o processo de uma atividade mental pela qual um indivíduo ou um grupo reconstitui o real ao qual ele é confrontado e lhe atribui uma significação específica. (ABRIC, 1987, p. 64). 
Moscovici (1978) percebe que os componentes das representações de grupos sociais distintos se organizam de formas diversas, constituindo diferentes universos de opinião e cada universo se divide em três dimensões: a atitude, a informação e o campo de representação ou imagem. A atitude ocorre quando o grupo representa algo após ter tomado uma posição em relação ao objeto, repercutindo em uma orientação favorável ou desfavorável para a ação a seu respeito. Para o autor, a atitude está conectada ao aspecto emocional e também à história de vida desses sujeitos. A informação é a organização do conjunto de conhecimentos que o grupo dispõe sobre o objeto, isso se refere tanto à qualidade quanto à quantidade de informações. O campo de representação remete à ideia de imagem ou de um modelo figurativo, estruturado por um conjunto mínimo suficiente e hierarquizado para representar o objeto. Essas três dimensões orientam o posicionamento de uma pesquisa em relação ao objeto. Para o autor, as representações sociais só podem ser analisadas em função da totalidade do discurso, sendo importante conhecer essas dimensões, pois influenciam diretamente nos resultados de estudos em Representações Sociais.

A partir do trabalho seminal de Moscovici, outros pesquisadores desenvolveram enfoques próprios para a TRS. Este trabalho desenvolve-se a partir da abordagem processual, destacando como referencial o trabalho de Jodelet (1989), forte representante desse enfoque. De acordo com Reateau et al (2012, p. 8), "Sobre esta base teórica geral do processo de produção de representações sociais, desenvolveu-se um campo de pesquisa amplo". Suas pesquisas priorizam os sentidos conduzidos nas comunicações que acontecem através da linguagem, por isso estudar as culturas é um fator preponderante para o desenvolvimento de seus estudos. Sua abordagem "enfoca o estudo dos sistemas de significados que expressam as relações que os indivíduos e grupos têm com seus ambientes" (RATEAU et al, 2012, p. 8).

A abordagem processual da TRS ajuda a ler a realidade dos sujeitos, buscando o conhecimento no sentido comum utilizado pelos indivíduos em sua experiência compartilhada cotidiana. Esses construtos, com status de teorias ingênuas, para Moscovici, são forjados na interação social, quando os sujeitos sociais estão em contato com os discursos que circulam no espaço público, servindo de guias para a ação.

Esse estudo buscou conhecer o processo de construção do pensamento social, a respeito de inovação pedagógica, seja ele constituído ou constituinte de representações. Para tanto, foi necessário investigar os processos de ancoragem e objetivação. 
A objetivação e a ancoragem são mecanismos que atuam simultaneamente no processo de elaboração de representações sociais. Normalmente, esses processos são descritos separadamente, visando à compreensão das estratégias cognitivas que são articuladas pelo grupo para construir a representação. Assim, Moscovici (2011, p. 70) esclarece que tal diferenciação tem por objetivo "facilitar a interpretação de características, a compreensão de intenções e motivos subjacentes às ações das pessoas, na realidade, formar opiniões". Compartimentando as representações nessas duas fases de elaboração, é possível melhor conhecer esses processos. No processo de objetivação, produz-se um efeito de apreensão, por concretização, de um novo conhecimento que antes se encontrava fluido, disperso e desorganizado. Na objetivação, o grupo “materializa” essa nova informação, transformando-a em algo compreensível e possível de ser entendido e comunicado rapidamente. De acordo com Moscovici (2012, p. 58).

\begin{abstract}
A objetivação tem como natureza um processo psíquico capaz de tornar familiar, de situar e de tornar presente aquilo que, em nosso universo interior, se encontra distanciado, aquilo que, de certa forma, está ausente. O resultado é uma "impressão" do objeto que se mantém durante o tempo que for necessário.
\end{abstract}

Entretanto, essa concretização da impressão do objeto não significa cristalização, pois a representação é viva e, portanto, mutável, dependendo do movimento que se estabelece no meio social. Contribuições de outras abordagens, em especial da estrutural, permitem dizer que a estrutura de uma representação é formada por um núcleo central e um sistema periférico. Este núcleo é "rígido", ou seja, mais resistente a mutações que os itens da periferia. Entretanto, embora seja mais estável do que o sistema periférico, ele nunca está paralisado, pois sofre a influência contínua da dinâmica das relações sociais. O sistema periférico funciona como "protetor" do núcleo central, adequando-se às contingências contextuais e situacionais, para permitir certa estabilidade das representações. Porém, Moscovici se refere às representações sociais como características das sociedades contemporâneas, em função de seu amplo poder de transformação em um tempo muito menor do que levaria em sociedades tradicionais.

A ancoragem é o processo complementar e simultâneo à objetivação. Essa parte do processo de representação ocorre a partir da conexão entre o novo objeto e os vários conhecimentos comuns ao grupo. Moscovici (2011, p. 61) fornece a ilustração da ancoragem com a imagem de alguém que "ancora um bote perdido em um dos boxes de nosso espaço social". Ela também poderia ser compreendida como um "enraizamento", 
pois as representações, pela ancoragem, lançam raízes que permeiam o conjunto de informações pré-existentes na consciência dos grupos sociais. Esse é um processo analítico, relativista, organizador e hierarquizante do conhecimento: analítico, porque, para que essa nova informação seja relacionada e encaixada no conjunto das informações que já existiam, o grupo precisa levantar as características relevantes do objeto para classificá-lo em uma determinada categoria: relativista, pois é preciso relacionar essas características com o conjunto de conhecimentos pré-existentes, de modo a significar o objeto, nomeando-o; organizador, porque reorganiza todo o conjunto de conhecimentos já existentes para que o novo possa tomar seu lugar e, hierarquizante, pois estabelece uma relação de hierarquia entre essa nova informação e as demais e promove níveis de importâncias entre elas.

É possível, portanto, dizer que ancorar é possibilitar, não um diálogo, mas um processo retórico, de fato, entre os conhecimentos, um embate entre o novo e o já estabelecido, uma negociação entre significados. Nesse sentido, falar de ancoragem implica compreender o universo consensual de que o sujeito dispõe. Esse ponto torna o estudo da ancoragem relativamente mais complexo e dispendioso que o da objetivação, pois demanda mais profundidade e amplitude de análise. Para Jodelet (1990), a partir da relação entre os processos de objetivação e ancoragem, é possível compreender como o sujeito confere significado ao objeto, como essa representação do novo se integra ao conjunto de representações existentes e como ela orienta as práticas dos sujeitos.

Por esses motivos, o viés da abordagem processual parece permitir a compreensão de como os sujeitos "professores da Educação Básica" representam o objeto "inovação pedagógica", por meio da percepção de como essas representações são objetivadas e de que maneira se ancoram nesse grupo.

\section{Metodologia}

A pesquisa foi realizada em uma escola do interior de Mato Grosso, no município de Novo Mundo, cuja população estimada em 2004 era de 6.046 habitantes e ocupa uma área de $5811,35 \mathrm{~km}^{2}$. O gráfico abaixo mostra a evolução do Índice de Desenvolvimento Humano do município e compara IDH renda com IDH longevidade e IDH educação. 
Gráfico 1: Evoçução IDH

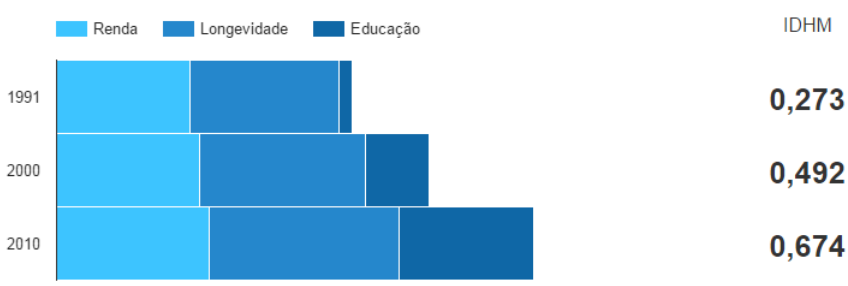

Fonte: PNUD (2004)

No caso do IDH educação do município, em 2010, 38,41\% da população com 18 anos ou mais possuía ensino fundamental completo; $92,53 \%$ da população com idade entre 5 a 6 anos estava frequentando a escola; 81,22\% com idade entre 11 e 13 anos estava frequentando os anos finais do ensino fundamental; $60,06 \%$ com idade entre 15 a 17 possuía ensino fundamental completo e; 49,40\% com idade entre 18 a 20 anos possuía ensino médio completo. Em relação aos dois gráficos que seguem, o primeiro apresenta a evolução do fluxo escolar por faixa etária no município de Novo Mundo, de 1991 até o ano de 2010 e o segundo apresenta o fluxo escolar de Novo Mundo, exclusivamente em 2010, e compara com a realidade mato-grossense e brasileira. (Só tem um, cadê o outro?

Gráfico 2: Evolução do fluxo escolar

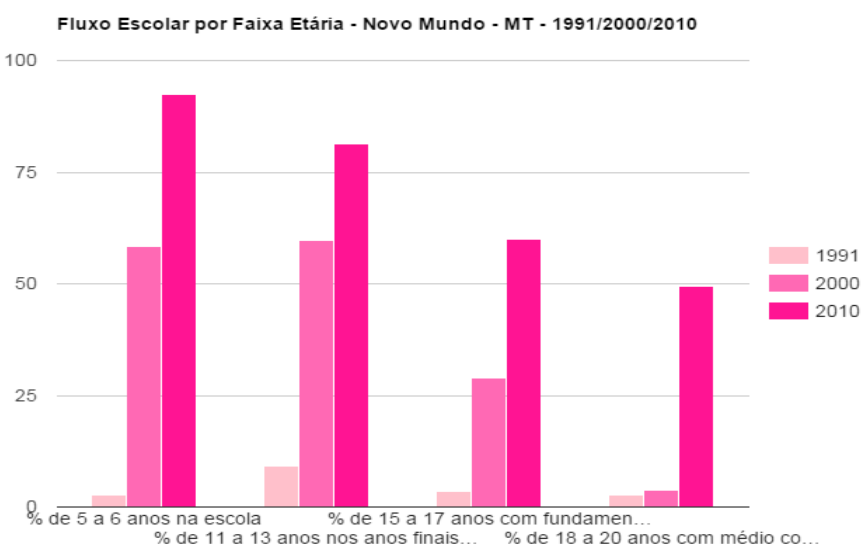

Fonte: PNUD, Ipea e FJP

Fonte: PNUD (2004)

O estudo foi realizado com dez professores da Educação Básica de uma escola estadual localizada no município de Novo Mundo, em Mato Grosso. Seis professores são formados em Pedagogia, dois professores são formados em Letras - Língua 
Portuguesa - e os outros dois, em Matemática, todos eles com mais de cinco anos de experiência na docência. Todos têm pós-graduação latu sensu. Para a coleta de dados foram realizadas entrevistas semiestruturadas no sentido de verificar como os sujeitos participantes estabelecem sua prática. As entrevistas foram gravadas, transcritas e, posteriormente, entregues aos docentes para que pudessem realizar as retificações que julgassem necessárias. Para confrontar as informações prestadas pelos sujeitosparticipantes, foi realizada uma observação não participante.

A Psicologia Social entende que as práticas de um sujeito se referenciam nas representações sociais que ele comunga com seu grupo de pertença. Se essas representações orientam as ações, então quando os sujeitos falam sobre suas crenças, opiniões, visões, valores e concepções de mundo, suas palavras permitem inferências de como suas práticas são orientadas. Nesse sentido, as falas (estratégias argumentativas organizadas para defender suas visões, valores, concepções de mundo, crenças e práticas) evocam as representações do objeto da pesquisa, por isso, optou-se por fazer a análise a partir do Modelo da Estratégia Argumentativa (MEA).

O MEA é uma técnica de análise proposta por Castro e Bolite-Frant (2011), baseia-se na Teoria da Argumentação proposta por Perelman (2007) e Perelman e Olbrechts-Tyteca (1992), para quem os processos de argumentação no discurso buscam a adesão do outro. As autoras defendem que ninguém fala simplesmente por falar e, do mesmo modo, ninguém argumenta contra aquilo que concorda ou que seja evidente, portanto, a análise parte da identificação de controvérsias.

As análises segundo o MEA devem ser feitas de acordo com os dez passos que indicam: I) a leitura exaustiva do material escrito ou transcrito; II) a constituição do corpus de análise, a partir dos objetivos da análise e da descrição das atividades em que os sujeitos estão engajados; III) a localização das controvérsias e seus motivos; IV) a enunciação das teses do locutor, que nem sempre estão explícitas e, nesses casos, devem ser escritas com enunciados claros pelo próprio analista; V) a busca dos argumentos utilizados para sustentar as teses; VI) a aplicação da tipologia de análise sobre os argumentos encontrados; VII) a montagem de esquemas referentes ao discurso; VIII) a interpretação para evidenciar os sentidos das afirmativas representadas no esquema; IX) a busca pelas evidências da interpretação nas próprias entrevistas e; X) a submissão da análise a critérios de validação.

As etapas que conduziram o estudo foram: Observação não participante, entrevistas semiabertas com os sujeitos participantes, análise das entrevistas segundo o 
MEA, inferências a partir da análise. Todo esse processo se apoiou no referencial teórico-metodológico da Teoria das Representações Sociais.

\section{Resultados e discussão}

As entrevistas destacam o próprio termo inovação como objeto de controvérsia. Muito diferentes foram as concepções sobre o termo, no entanto, havendo muita convergência também. Ao que parece, esses professores ainda procuram um sentido mais claro para o termo, exibindo uma quase desconfiança ao tê-lo como centro do debate.

As falas dos sujeitos-participantes evidenciam os elementos "mudar", "diferenciar", "melhorar" e "novidade" como aqueles que objetivam suas representações sociais a respeito de Inovação Pedagógica. Essas representações estão ancoradas em saberes de formação docente inicial, que podem ser claramente descritos pelos termos "novas tecnologias" e "construtivismo".

Os sujeitos-participantes não apresentam homogeneidade em relação a como veem o trabalho que realizam, sete deles indicam que sua prática é inovadora, três deles relataram não ter uma prática que consideram inovadora. Os que acreditam ter disseram que isso se deve, em parte, à formação, mas também à própria vivência prática. "Não é minha prática inovadora, mas acho que é o que a maioria dos professores fazem o que é correto fazer" (professor 1), "a gente aprende na faculdade que devem ser desenvolvidos trabalhos a fim de buscar novas formas de ensino, partindo de métodos que levam os alunos a construir o conhecimento (professor 5). Como exemplificam essas falas, os professores compreendem inovação a partir do que vivenciam com seus pares e, na maioria das respostas, com o que aprenderam em sua formação inicial.

Foi interessante perceber que relacionam inovação ao "construtivismo" e a "novidades tecnológicas" no ambiente escolar. "Inovar é estar sempre buscando estar a par desse mundo tecnológico aí... os alunos são muito conectados, o professor precisa sempre inovar" (professor 2). Nessa fala, verifica-se inclusive a ideia de que se inova por que há a demanda por parte dos estudantes. Parece descrever que a inovação é puxada pelo aluno e não proposta pelo professor, isso que é bastante compatível com as ideias construtivistas. 
Todos os sujeitos disseram que aprenderam como ser professor pela observação de seus professores. Do mesmo modo que explicam que aprenderam como não ser professor, a partir da observação do que consideram maus exemplos de prática docente.

Três sujeitos disseram não ter uma prática inovadora, explicam que, apesar de compreenderem o movimento de todas as políticas no sentido de uma inovação, não creem que as autoridades proporcionem condições para que exerçam sua prática de forma inovadora, para eles, faltam recursos materiais. Além disso, relatam que a rotina e o excesso de trabalho são grandes inimigos da inovação em práticas pedagógicas. "Não vejo o que eu faço como inovador, nem daria tempo, é tanta coisa que tenho que cumprir" (professor 3).

Todos concordam que as condições a que seus alunos são submetidos como longas distâncias entre suas residências e a escola, necessidade de trabalhar, falta de recursos materiais, dificultam a realização de uma prática inovadora. Tais condições não possibilitam tempo para a criação de atividades extracurriculares e de contra turno, isso, para os sujeitos, dificulta a inovação. Outro ponto mencionado por nove professores foi a falta de articulação entre a prefeitura e o governo estadual, o que dificulta a melhoria nas condições de trabalho. O não engajamento dos pais dos alunos também foi apontado, por quatro sujeitos, como fator crítico.

Os professores que acreditam ter práticas inovadoras, quando questionados sobre as dificuldades rotineiras, confirmam que essas dificuldades representam entraves para a inovação, mas dizem "driblar" essas dificuldades conforme aparecem. Quando questionados sobre o modo como driblam essas dificuldades, eles dizem que nem sempre conseguem "driblar" e inovar, mas afirmam que, quando têm o apoio da Secretaria de Educação e das autoridades escolares, conseguem fazer o que precisam para inovar.

Em relação ao termo "mudar", percebe-se uma aproximação à ideia de transformação daquilo que está posto como realidade, uma mudança no existente. Conforme indicam Garcia (2009) e Teixeira (2010), o termo “inovação pedagógica” tem adquirido vários significados no contexto educacional, tanto no campo acadêmico quanto no das políticas públicas, podendo referir-se às mudanças, transformações ou rupturas. No caso dos sujeitos participantes dessa pesquisa, pressupõem uma modificação no ambiente exterior, externo ao professor e ao aluno.

Essa transformação ocorreria a partir da técnica de ensinar, no fazer do próprio professor, mas ainda assim é externo a ele, não se trata de mudança diretamente 
relacionada com os saberes que direcionam sua prática, pois os sujeitos não sugerem que há necessidade de mudar o pensamento para isso, significa mudar o modo de ensinar, com o objetivo de melhorar o processo ensino-aprendizagem. Fatores como a qualidade de trabalho para a preservação da saúde do próprio professor, por exemplo, não foram contemplados por nenhum professor, apenas a relação ensino-aprendizagem. “aprendi a sempre olhar tudo com desconfiança, sempre dá para mudar o jeito de fazer para melhorar a qualidade do trabalho, partindo do construtivismo" (professor 9). Desse modo, a ideia de inovação alheia ao sujeito é fruto de uma concepção oriunda de uma visão relacionada à fábrica, em que inovação consistiu em um novo método de produção, abrindo espaço para o novo, portanto, há grande propensão a identificá-la como técnica, o que para Nogaro e Battestin (2016, p. 360) "a distanciaria de uma compreensão de educação cuja perspectiva é a formação do todo do sujeito".

"Diferenciar" tenciona para o não igual ao que se fez do modo errado. Mais uma vez os sujeitos direcionam a ideia de inovação pedagógica para a questão da técnica envolvida no processo ensino-aprendizagem. Entretanto, quando questionados sobre o por qual motivo diferenciar, as respostas são diversas como para melhorar, para fazer do jeito certo, para o aluno aprender. O sentido de "diferenciar" é explorado por Veiga (2003),

Inovar é, portanto, introduzir algo diferente dentro do sistema, para produzir uma mudança organizacional descontextualizada. Este processo deixa de lado os sujeitos como protagonistas, desprezando as relações e as diferenças entre eles, não reconhecendo as relações de força entre o institucional e o contexto social mais amplo (VEIGA, 2003, p. 270).

O temo "melhorar" indica que mesmo aqueles que dizem ter uma prática inovadora sentem que seu trabalho não está completamente correto ou bom, pois seu trabalho precisa "melhorar". Essa melhora viria por meio dos elementos "mudar" e “diferenciar”. Nesse sentido, Saviani (1980) apresenta, como um dos níveis de inovação na esfera educacional, ser a educação alterada nas suas próprias finalidades. Buscam-se os meios considerados mais adequados e eficazes para se atingir as novas finalidades.

A noção de "novidade" sugere uma grande confusão constatada a partir da relação inovação x novidade. Oito dos professores entrevistados acreditam que novidades tecnológicas por si só representam inovação pedagógica. Alguns, inclusive, dizem se sentir culpados por não conseguir acompanhar as tecnologias. 
É possível verificar nas falas dos entrevistados que essas representações se ancoram em sua formação inicial, pois, quando são indagados sobre os termos que objetivam suas representações, todos relacionam tais elementos ao que foi aprendido em sua formação inicial, como nos exemplos: "nunca falaram sobre inovação pedagógica, mas sempre sobre trabalhar de forma a mudar a realidade" (professor 3), "foi muito trabalhado o construtivismo para melhorar a educação" (professor 9), "todo pedagogo sai da faculdade com isso na cabeça, a importância que tem a inovação e o uso das tecnologias" (professor 10). Esses trechos mostram que suas representações de “inovação pedagógica" estão ancoradas no que aprenderam quando eram alunos da graduação.

\section{Considerações finais}

Alguns pontos de síntese podem ser elencados: os sujeitos participantes veem a "inovação pedagógica" como algo externo a si e, por vezes, distante; relacionam o termo à tecnologia; não se percebem como sujeitos promotores da inovação; apresentam vários entraves de ordem material a uma prática pedagógica inovadora.

Ficou claro com a análise que a maioria dos sujeitos participantes não vê a inovação como algo rotineiro e, sim, como eventos específicos e isolados, como atividades de contra turno, visitas externas a feiras de ciências, por exemplo. Aqueles que relacionam a inovação à rotina escolar, não desvinculam a inovação ao uso de "novas tecnologias", o que confere um sentido de "novidade" ao termo "inovação pedagógica".

Confrontando com a observação e literatura revista com a análise das entrevistas, verificamos que os professores entendem inovação como algo alheio a eles, como aquilo que está fora. No caso específico dos sujeitos-participantes desse estudo, o termo “inovação pedagógica" está mais relacionado a novas tecnologias e técnicas didáticas que a uma postura ou desejo ou à própria noção de pedagogia.

Por fim, é importante ressaltar que a inovação é de ordem cultural e filosófica e não somente de ordem prática. A noção de que "inovação pedagógica" depende de algo esporádico e que está externa a eles representa um grande entrave à transformação na educação do Brasil.

\section{REFERÊNCIAS}


ALVES-MAZZOTTI, A. J. Representação do trabalho do professor das séries iniciais: a produção do sentido de "dedicação". R. bras. Est. pedag, Brasília, v. 89, p. 522-534, set./dez., 2008.

BEHRENS, M. A.O paradigma emergente e a prática pedagógica. Curitiba: Champagnat, 1999. $131 \mathrm{p}$.

BOLZAN, D. P. V. A construção do conhecimento pedagógico compartilhado: reflexões sobre o papel do Professor universitário. In: Anais da V ANPED Sul, Curitiba, PR, p. 1-15, 2004. Disponivel em:

$<$ Http://www.portalanpedsul.com.br/admin/uploads/2004/mesa_redond/mesa_redonda/0 6_47_00_a_construcao_do_conhecimento_pedagogico_compartilhado_reflex.pdf $>$. Acesso em: 14 abr. 2017.

BRAGANÇA, I. F. D. S.; MOREIRA, L. C. P. Formação e profissionalização docente no Brasil: instituições, práticas educativas e História. Revista Eletrônica Pesquiseduca, p. 43-62, 2013.

CABRAL NETO, A.; CASTRO, A. M. D. A. Gestão Educacional na América Latina: delineamentos e desafios para os sistemas de ensino. In: EYNG, A. M.; GISI, M. L.(Org.). Política e gestão da educação superior: desafios e perspectivas. Ijui: Unijui, 2007.

CÂNDIDO, F. Francineide. Aprendizagem significativa em uma sala de apoio aos alunos do Ensino Fundamental: um olhar sobre as práticas pedagógicas. Dissertação apresentada, mas não publicada. UMa. Funchal, Portugal. 2013.

CAMPOS, P. H. O dilema dos "herdeiros de Durkheim": classes, grupos ou instituições? In: E. M. Q. O. Chamon; P. A. Guareschi; \& P. H. F. Campos (Org.). Textos e debates em representações sociais. Porto Alegre: ABRAPSO: [s.n.], 2014.

CASTRO, M. R.; BOLITE FRANT, J. Modelo da estratégia argumentativa. Curitiba: UFPR, 2011.

DIAS SOBRINHO, J. Democratização, qualidade e crise da educação superior: faces da exclusão e limites da inclusão. Educ. Soc. Campinas, v. 31, n. 113, p. 1223-1245, out.dez. 2010. Disponível em <HTTP://cedes.unicamp.br>. Acesso em: 20 maio 2017.

DINIZ-PEREIRA, J. E. O ovo ou a galinha: a crise da profissão docente e a aparente falta de perspectiva para a educação brasileira. R. bras. Est. pedag. Brasília, v. 92, n. 230, p. 34-51, jan./abr 2011.

DOLL JR, W. E. Os remanescentes do currículo. In: Currículo: uma perspectiva pósmoderna. Porto Alegre: ArtMed, 2002. (p.55-72). 
DOMINGOS, S. D. CASTRO M. R. Representações sociais de professores formadores sobre a prática de professores da Educação Básica. Rev. educ. PUCCamp., Campinas, 22(2):299-315, maio/ago., 2017.

FINO, C. (2008) Inovação Pedagógica: Significado e Campo (de Investigação). In: MENDONÇA, A.; BENTO, A. (Orgs.). Educação em Tempo de Mudança. (p. 277 287). MadeiraCIE: Grafimadeira.

FOUCAULT, M. Vigiar e punir. Petrópolis: Vozes, 1977.

FOUCAULT, M. Vigiar e punir: nascimento da prisão. Petrópolis: Vozes, 1987.

GATTI, B. A.; NUNES, M. M. Formação de professores para o ensino

fundamental: estudo de currículos das licenciaturas em pedagogia, língua portuguesa, matemática e ciências biológicas. São Paulo: FCC/DPE: [s.n.], v. 29, 2009.

GARCIA, P. S. um estudo sobre a inovação como estratégia de formação contínua de professores ciências. In: VII ENCONTRO NACIONAL DE PESQUISA EM EDUCAÇÃO EM CIÊNCIAS. Anais.... ABRAPEC: Florianópolis, 2009.

GOUVEIA, M. F. B. P. Gestão flexível do currículo rumo à diferenciação pedagógica. Contributos para a promoção de aprendizagens significativas. Tese apresentada à Universidade da Madeira. Funchal: 2012.

JODELET, D. Representações sociais: um domínio em expansão. In: JODELET, D. (Org.). As Representações sociais. Rio de Janeiro: Eduerj, 1990.

KUHN, T. S. The Structure of Scientific Revolutions. Chicago: Universisty of Chicago Press.

LAVE, J. \& WENGER, E. (1991). Situated Learning: Legitimate Peripheral Participation. Cambridge: Cambridge University Press.

LIBÂNEO, J. C. Adeus professor, adeus professora?: novas exigências educacionais e profissão docente. 10. ed. São Paulo, SP: Cortez, 2007.

LIMA, R. D. C. P.; FERNANDES, M. C. D. S. G.; GONÇALVES, M. F. C.

Representações sociais de alunas de Pedagogia sobre o trabalho docente: estágio e experiência. NUANCES: Estudos sobre Educação, v. 16, n. 17, 2011.

LÜDKE, M.; BOING, L. A. Do trabalho à formação de professores. Cadernos de pesquisa, v. 42, n. 146, p. 428-451, maio/ago. 2012. 
MELO, M. S. T. Inovações pedagógicas no currículo dos cursos de formação de profissionais de educação física: contribuições teórico-metodológicas da prática pedagógica. Tese de doutorado, Universidade Federal de Pernambuco, 2007.

MIZUKAMI, Maria da Graça Nicoletti. Ensino: as abordagens do processo. São Paulo: EPU, 1986. 119 p.

MOSCOVICI, S. A representação social da psicanálise. Rio de Janeiro: Zahar, 1978.

MORIN, E. Os sete saberes necessários à educação do futuro. Tradução de Catarina Eleonora F. da Silva e Jeanne Sawaya. Revisão técnica de Edgar de Assis Carvalho. São Paulo: Cortez; Brasília, DF: UNESCO, 2000.

NOGARO, A. BATTESTIN, C. Sentidos e Contornos da Inovação na Educação. Holos, Ano 32, v. 2, 2016.

PERELMAN, C. O império retórico: retórica e argumentação. Rio de Janeiro, RJ: J Vrin, 2007.

PERELMAN, C.; OLBRECHTS-TYTECA, L. Traité de l'argumentation. Bruxelles :Editions de l'Université de Bruxelles, 1992.

ROCHA, H. O. Programa Ensino Médio Inovador - ProEMI no Maranhão: necessidades formativas de professores e práticas pedagógicas inovadoras em escolas públicas de São Luís. Tese de doutorado, Universidade Federal do Rio Grande do Norte. 2016.

SÁ, C. P. A construção do objeto de pesquisa em representações sociais. Rio de Janeiro: EdUERJ, 1998.

SAVIANI, D. Formação de professores: aspectos históricos e teóricos do problema no contexto brasileiro. Revista Brasileira de Educação, Campinas, jan. 2009. Disponivel em: <http://www.scielo.br/pdf/rbedu/v14n40/v14n40a12.pdf>. Acesso em: 14 abr. 2017.

SAVIANI, D. A Filosofia da Educação e o problema da inovação em educação. In: GARCIA, W.E. (Org.) Inovação educacional no Brasil. S. Paulo: Cortez, 1980.

TARDIF, M. Saberes docentes e formação profissional. 4 ed. Petrópolis, RJ: Vozes, 2002.

TEDESCO, J. C; FANFANI, E. T. Nuevos maestros para nuevos estudiantes. In: PEARLMAN, M (Org.). Maestros en América Latina: nuevas perspectivas sobre su Formación y Desempeno. Washington: Preal, p. 67-96, 2004. 
TEIXEIRA, C. M. F. Inovar é preciso: concepções de inovação em educação dos programas Proinfo, Enlaces e Educar. Dissertação (Mestrado em Educação). Programa de PósGraduação em Educação. Universidade do Estado de Santa Catarina, 2010

TOFFLER, Alvin. Choque do futuro. Lisboa: Edição Livros do Brasil, 1970.

VEIGA, I. P. A. Inovações e projeto político-pedagógico: uma relação regulatória ou emancipatória? Cad. Cedes, Campinas, v. 23, n. 61, p. 267-281, dezembro 2003.

\section{Como referenciar este artigo}

DOMINGOS, Silvio Duarte.; CASTRO, Mônica Rabello De. Representações sociais de inovação pedagógica por professores da educação básica. Temas em Educação e Saúde, Araraquara, v.14, n.1, p. 98-120, jan./jun., 2018. ISSN: 1517-7947. DOI: 10.26673/rtes.v14.n1.2018.11206

Submetido em: 19/03/2018

Aprovado em: 04/05/2018 